\title{
The set point for maternal glucose homeostasis is lowered during late pregnancy in the rat: the role of the islet beta-cell and liver
}

\author{
C. J. Nolan, J. Proietto
}

University of Melbourne, Department of Medicine, Royal Melbourne Hospital, Victoria, Australia

\begin{abstract}
Summary The aim of this study was to determine the effects of late pregnancy on the ability of insulin to suppress maternal hepatic glucose production in the rat. Unlike in most previous studies, suppression of hepatic glucose production was measured at levels of glycaemia above the relatively hypoglycaemic basal pregnant level. Glucose kinetics were measured using steady-state tracer methodology in chronically catheterised, conscious virgin control and pregnant rats, firstly, during basal and low-dose hyperinsulinaemic euglycaemic clamp conditions and secondly, during a three-step glucose infusion protocol (glucose infusion rates of 0,60 and $\left.150 \mu \mathrm{mol} \cdot \mathrm{kg}^{-1} \cdot \mathrm{min}^{-1}\right)$. During the clamps, plasma glucose levels were not different $(6.1 \pm 0.4$ vs $6.5 \pm 0.3 \mathrm{mmol} / \mathrm{l}$, pregnant vs virgin; N.S.), but plasma insulin levels were higher in the pregnant rats $(242 \pm 30$ vs $154 \pm 18 \mathrm{pmol} / \mathrm{l}$, pregnant vs virgin; $p<0.05$ ) most probably due to stimulated endogenous insulin release in this group. Hepatic glucose production was suppressed from basal levels by $41 \%$ in virgin and $90 \%$ in pregnant rats. During the
\end{abstract}

glucose infusion studies, at matched insulin levels (147 \pm 10 vs $152 \pm 14 \mathrm{pmol} / \mathrm{l})$, but at plasma glucose levels which were much lower in the pregnant rats $(5.5 \pm 0.2$ vs $8.4 \pm 0.6 \mathrm{mmol} / \mathrm{l}$, pregnant vs virgin; $p<0.0001$ ), hepatic glucose production was shown to be suppressed by a similar degree in both groups ( $41 \pm 5$ vs $51 \pm 5 \%$ from basal, pregnant vs virgin; N.S.). Both the plasma insulin and percentage suppression of hepatic glucose production dose responses to plasma glucose were markedly shifted to the left indicating that the plasma glucose set point is lowered in pregnancy. In conclusion, suppression of hepatic glucose production by insulin is not impaired and the set point for plasma glucose homeostasis is lowered during late pregnancy in the rat. [Diabetologia (1996) 39: 785-792]

Keywords Pregnancy, glucose homeostasis, hyperinsulinaemic euglycaemic clamp, hepatic glucose production, insulin secretion, rat.
Adaptation of the maternal hormonal and metabolic milieu during late pregnancy is undoubtedly geared to the maintenance of an optimal fuel mix for transfer via the placenta to the developing fetus [1-3]. In the fasting state, fetal glucose demands are met by an

Received: 2 October 1995

and in final revised form: 1 February 1996

Corresponding author: Dr. C.J.Nolan, University of Melbourne, Department of Medicine, Royal Melbourne Hospital, Victoria, 3050, Australia

Abbreviations: HGP, Hepatic glucose production; Ra, glucose appearance rate; $\mathrm{Rd}$, glucose disposal rate; GIR, glucose infusion rate; MCR, metabolic clearance rate. increase in maternal hepatic glucose production [47] and a reduction in maternal peripheral glucose utilisation $[4,8,9]$. In the fed state, maternal peripheral insulin resistance enables further 'sparing' of glucose for feto-placental use by limiting maternal peripheral glucose uptake $[4,8,10-12]$. The roles of the maternal endocrine pancreas and liver in glucose homeostasis during the fed state in late pregnancy, however, are not well understood.

It is well established that the insulin secretory response of maternal islet beta cells to glycaemic stimuli is markedly enhanced late in normal pregnancy $[1-3,13-15]$. Generally, it is believed that this betacell hyperresponsiveness is compensatory for the 
insulin resistance. It is not known, however, whether the resultant marked postprandial elevations in portal insulin have a role in adapting hepatic glucose and intermediary metabolism. Central to the understanding of this is the unresolved issue of whether the maternal liver is, or is not, resistant to the action of insulin in pregnancy.

Previous investigators using hyperinsulinaemic euglycaemic clamp techniques in rats $[16,17]$ and rabbits $[10,18,19]$ have concluded that, in pregnancy, the suppression of hepatic glucose production (HGP) by insulin is impaired. In contrast, using the same technique, the suppression of HGP or hepatic insulin sensitivity has been shown to be unchanged in women [7] and enhanced in sheep [20]. The validity of the conclusions of these studies, however, needs careful consideration. Firstly, in all the animal studies $[10,16-19]$ the clamps were performed at the basal glycaemia of each group which was invariably lower in the pregnant compared to non-pregnant groups. A direct comparison between pregnant and non-pregnant animals, therefore, is not entirely valid as insulin is dependent on the prevailing glucose level for its ability to suppress HGP [21-23]. Secondly, in all these animal studies, additional glucose tracer was not added to the glucose infusate so as to avoid large falls in glucose specific activity during the clamp procedures. It has been shown that tracer estimations of HGP during hyperinsulinaemic euglycaemic clamps can be underestimated if the glucose infusate is not labelled [24]. In the human study [7], valid conclusions could be made as the clamps were performed at $5.0 \mathrm{mmol} / 1$ in all groups and additional tracer was added to the glucose infusate.

In the current studies we set out to determine, with the methodological difficulties of the previous studies in mind, the effects of late pregnancy in the rat on the suppressibility of HGP by insulin. Hyperinsulinaemic euglycaemic clamp procedures were performed in chronically catheterised, conscious control virgin and pregnant rats. Clamp glycaemia was matched in both groups at the virgin basal level. The suppression of HGP was also assessed in control virgin and pregnant rats during a glucose infusion protocol in which glycaemia was allowed to rise above the euglycaemic ranges.

\section{Materials and methods}

Experimental animals. Female, age-matched (100 days on day 0) Sprague Dawley rats (Monash University Animal Facility, Clayton, Vic., Australia) were used. The studies were performed in unstressed, chronically catheterised, conscious, control virgin and pregnant rats. All animals were housed in a temperature controlled environment $\left(22^{\circ} \mathrm{C}\right)$ and were subject to controlled lighting ( $12 \mathrm{~h}$ dark/ $12 \mathrm{~h}$ light). Animals had free access to water and standard laboratory chow (Barastoc, Pakenham, Vic., Australia). Chronic bilateral jugular catheters were inserted under intraperitoneal pentobarbitone (Boehringer Ingelheim, Artarmon, NSW, Australia) anaesthesia $(60 \mathrm{mg} / \mathrm{kg}$ ) on day 0 . The intravenous part of the catheters was made from silastic tubing (internal diameter (ID) 0.020 inches; Dow Corning, Midland, Mich., USA), while the subcutaneous and exteriorised parts were made from medical grade polyethylene tubing (ID $0.58 \mathrm{~mm}$; Dural Plastics, Auburn, NSW, Australia). The first catheter was positioned via the right jugular vein in the right atrium for blood sampling. The second, shorter catheter was placed in the left jugular vein for infusions. Once secured into the veins, the free ends were tunnelled subcutaneously to the back of the neck, exteriorised through a skin incision and flushed with $1 \mathrm{ml} 0.9 \% \mathrm{NaCl}$ containing $10 \mathrm{U} / \mathrm{ml}$ heparin (Bull Laboratories, Mulgrave, Vic, Australia). The exteriorised ends were then heat sealed $3 \mathrm{~cm}$ from the skin. Following the surgery, the rats were individually housed in specially designed metabolic cages and allowed to recover.

All metabolic tests were performed on day 7 at which time the pregnant rats were at 19 days gestation. Laboratory chow was removed at 06.00 hours, the catheters were connected to infusion and sampling pumps (Gilson Minipuls 2; Villiers, Lebel, France) at 08.00 hours and the experiments commenced at 10.00 hours (time $0 \mathrm{~min}$ ). In all experiments, the sampling catheters and connecting tubing were filled with heparinised saline to maintain patency between blood samples. In order to avoid anaemia and intravascular volume depletion, the erythrocytes from all blood samples were resuspended in heparinised saline and transfused back to the same rat periodically through the respective experiment. Throughout the experiments the rats were allowed to move freely within the confines of the metabolic cages. In all experiments a baseline blood sample $(300 \mu \mathrm{l})$ was taken at time $0 \mathrm{~min}$. Two series of studies were performed.

Hyperinsulinaemic euglycaemic clamp studies. Whole-body glucose kinetics were measured under basal and hyperinsulinaemic euglycaemic conditions in virgin and pregnant rats as follows. A primed ( $5 \mathrm{~min}$ priming dose of $12.5 \mu \mathrm{Ci} / \mathrm{kg}$ ), continuous infusion $\left(0.25 \mu \mathrm{Ci} \cdot \mathrm{kg}^{-1} \cdot \mathrm{min}^{-1}\right)$ of $\left[6^{-3} \mathrm{H}\right]$ glucose (New England Nuclear, Boston, Mass., USA) was commenced at time $0 \mathrm{~min}$. A primed ( $10 \times$ continuous rate for $5 \mathrm{~min}$ ) continuous infusion of insulin (Actrapid; CSL-Novo, North Rocks, NSW, Australia) at either 0 (basal studies), 12.0 (virgin clamp) or $9.6 \mathrm{pmol} \cdot \mathrm{kg}^{-1} \cdot \mathrm{min}^{-1}$ (pregnant clamp) was also commenced at time $0 \mathrm{~min}$. The $20 \%$ lower insulin infusion rate was used in the pregnant clamp studies as the volume of distribution of maternal insulin in the pregnant rat does not include the fetus. The $\left[6-{ }^{3} \mathrm{H}\right]$ glucose and insulin were infused together in a solution of $0.9 \% \mathrm{NaCl}$ and Haemaccel (ratio 9:1). During the clamp studies blood glucose was measured every $10 \mathrm{~min}$ and accordingly a variable $20 \%$ glucose infusion was used to maintain plasma glucose at $6.0 \mathrm{mmol} / \mathrm{l}$ in both groups. To avoid large fluctuations in plasma glucose specific activity, $7.0 \mu \mathrm{Ci} / \mathrm{ml}$ $\left[6-{ }^{3} \mathrm{H}\right]$ glucose was added to the $20 \%$ glucose infusate. Steadystate plasma glucose and exogenous glucose infusion rates were achieved in the clamp studies by $80 \mathrm{~min}$. Three blood samples $(300 \mu \mathrm{l})$ spaced at 10 -min intervals were taken from time $100 \mathrm{~min}$ in both the basal and clamp studies for plasma glucose, insulin and $\left[6-{ }^{3} \mathrm{H}\right]$ glucose specific activity determinations. At the end of the experiments timed collections of the infusates were obtained for accurate determination of the $\left[6-{ }^{3} \mathrm{H}\right]$ glucose and exogenous cold glucose infusion rates.

Glucose infusion studies. Whole-body glucose kinetics were measured basally and during low- and high-dose glucose infusions in virgin and pregnant rats. A primed (5 min priming dose of $12.5 \mu \mathrm{Ci} / \mathrm{kg})$ continuous infusion $\left(0.25 \mu \mathrm{Ci} \cdot \mathrm{kg}^{-1}\right.$. 
Table 1. Plasma glucose and insulin levels, GIR, Total Ra, HGP and MCR during the basal and hyperinsulinaemic euglycaemic clamp studies in virgin and pregnant rats

\begin{tabular}{|c|c|c|c|c|}
\hline & \multicolumn{2}{|l|}{ Virgin } & \multicolumn{2}{|l|}{ Pregnant } \\
\hline & Basal & Clamp & Basal & Clamp \\
\hline Glucose $(\mathrm{mmol} / \mathrm{l})$ & $6.7 \pm 0.2$ & $6.5 \pm 0.3$ & $4.8 \pm 0.1^{\mathrm{b}}$ & $6.1 \pm 0.4$ \\
\hline Insulin $(\mathrm{pmol} / \mathrm{l})$ & $79 \pm 6$ & $154 \pm 18$ & $89 \pm 9$ & $242 \pm 30^{c}$ \\
\hline $\operatorname{GIR}\left(\mu \mathrm{mol} \cdot \mathrm{kg}^{-1} \cdot \min ^{-1}\right)$ & - & $80 \pm 5$ & - & $135 \pm 14^{\mathrm{d}}$ \\
\hline Total $\mathrm{Ra}\left(\mu \mathrm{mol} \cdot \mathrm{kg}^{-1} \cdot \mathrm{min}^{-1}\right)$ & $49 \pm 3$ & $109 \pm 5$ & $60 \pm 3^{a}$ & $140 \pm 11^{\mathrm{c}}$ \\
\hline $\mathrm{HGP}\left(\mu \mathrm{mol} \cdot \mathrm{kg}^{-1} \cdot \mathrm{min}^{-1}\right)$ & $49 \pm 3$ & $29 \pm 3$ & $60 \pm 3^{a}$ & $6 \pm 6^{d}$ \\
\hline $\operatorname{MCR}\left(\mathrm{ml} \cdot \mathrm{kg}^{-1} \cdot \min ^{-1}\right)$ & $7.3 \pm 0.4$ & $17 \pm 1$ & $12.6 \pm 0.7^{b}$ & $23 \pm 2^{c}$ \\
\hline
\end{tabular}

Values are means \pm SEM of $7-8$ rats in each group. ${ }^{\mathrm{a}} p<0.05,{ }^{\mathrm{b}} p<0.0001$ vs basal virgin; ${ }^{\mathrm{c}} p<0.05,{ }^{\mathrm{d}} p<0.01$ vs clamp virgin

$\left.\min ^{-1}\right)$ of $\left[6{ }^{3} \mathrm{H}\right]$ glucose in $0.9 \% \mathrm{NaCl}$ was commenced at time $0 \mathrm{~min}$. In addition, $10 \%$ glucose was infused at a constant rate of $60 \mu \mathrm{mol} \cdot \mathrm{kg}^{-1} \cdot \mathrm{min}^{-1}$ (low dose) from time 120 to $180 \mathrm{~min}$ and $25 \%$ glucose was infused at a constant rate of $150 \mu \mathrm{mol}$ $\mathrm{kg}^{-1} \cdot \mathrm{min}^{-1}$ (high dose) from time 180 to $240 \mathrm{~min}$. To avoid large fluctuations in plasma glucose specific activity, 3.5 and $8.75 \mu \mathrm{Ci} / \mathrm{ml}\left[6-{ }^{3} \mathrm{H}\right]$ glucose was added to the $10 \%$ and $25 \%$ glucose infusates, respectively. Three blood samples $(300 \mu \mathrm{l})$ spaced at 10 -min intervals were taken at the end of each infusion period (i.e. from time $100 \mathrm{~min}, 160 \mathrm{~min}$ and $220 \mathrm{~min}$ ) for plasma glucose, insulin and $\left[6-{ }^{3} \mathrm{H}\right]$ glucose specific activity determinations. At the end of the experiments, timed collections of all the infusates were obtained for accurate determination of the $\left[6-{ }^{3} \mathrm{H}\right]$ glucose and exogenous cold glucose infusion rates for each period.

Analytical methods. Glucose levels in blood and plasma were measured using a 23 AM YSI Glucose Analyser (Yellow Springs Instrument Company, Yellow Springs, Ohio, USA). Plasma insulin was measured using a double antibody method (Phadeseph; Pharmacia, Uppsala, Sweden). To measure plasma glucose specific activity $50 \mu \mathrm{l}$ of the plasma samples were deproteinised with an equal volume of saturated $\mathrm{Ba}(\mathrm{OH})_{2}$ and $5.5 \% \mathrm{ZnSO}_{4}$. One hundred microlitres of each supernatant was passed through an anion exchange resin column (Dowex-2X8, 200-400 mesh, Cl form; Bio-Rad Laboratories, Richmond, Calif., USA) to remove labelled charged metabolites (lactate/pyruvate). The columns were washed with distilled water and the eluents were dried $\left(60^{\circ} \mathrm{C}\right)$ to remove tritiated water. The dried eluents were resuspended in $4 \mathrm{ml}$ water and after addition of $8 \mathrm{ml}$ scintillation fluid (Readyvalue; Beckman, Palo Alto, Calif., USA) were counted for $\left[{ }^{3} \mathrm{H}\right] \mathrm{dpm}$ in the gel phase using a beta-scintillation counter (Beckman Instruments, Irvine, Calif., USA). The timed $\left[6-{ }^{3} \mathbf{H}\right]$ glucose infusate collections were also dried, resuspended and counted as above.

Calculations. At steady state, the total body glucose appearance rate ( $\mathrm{Ra}$ ) ( $\mu \mathrm{mol} / \mathrm{min}$ ) is equal to the total body glucose disposal rate ( $R d)$ and $R a$ equals the glucose tracer infusion rate $(\mathrm{dpm} / \mathrm{min})$ divided by the plasma glucose specific activity $(\mathrm{dpm} / \mu \mathrm{mol})$. In the fasted state, $\mathrm{Ra}$ is equal to the hepatic glucose production rate (HGP). During the hyperinsulinaemic clamp and the glucose infusion studies, $R a$ is equal to the sum of HGP and the rate of infused unlabelled glucose. Thus, HGP is equal to the difference between the tracer-determined $\mathrm{Ra}$ and the directly measured glucose infusion rate (GIR). The plasma glucose metabolic clearance rate (MCR) $(\mathrm{ml} / \mathrm{min})$ equals $\mathrm{Rd}\left(\mu \mathrm{mol} \cdot \mathrm{kg}^{-1} \cdot \mathrm{min}^{-1}\right)$ divided by the plasma glucose concentration $(\mu \mathrm{mol} / \mathrm{ml})$.

\section{Statistical analysis}

Results are presented as mean \pm SEM. Statistical significance of differences were assessed by the Student's unpaired or paired $t$-test.

\section{Results}

All the rats used in the study recovered well from the surgery at day 0 and had positive weight gains from at least day 3. Over all the experiments, the pregnant (P) compared to virgin (V) rats gained more weight between day 0 and day 7 ( $44 \pm 3$ vs $5 \pm 2 \mathrm{~g}, \mathrm{P}$ vs V; $p<0.0001)$ and were heavier on day $7(317 \pm 5$ vs $257 \pm 4 \mathrm{~g}, \mathrm{P}$ vs $\mathrm{V} ; p<0.0001)$

Hyperinsulinaemic euglycaemic clamp studies. Plasma glucose specific activities were shown to be in steady state over the 20-min sampling period in both the virgin and pregnant rats during both the basal and clamp experiments. Importantly, the addition of $\left[6-{ }^{3} \mathrm{H}\right]$ glucose tracer to the glucose infusate of the clamp studies avoided the problem of a delay in reaching steady state and, therefore, the potential problem of HGP underestimation [24].

The basal and clamp plasma glucose, plasma insulin and whole-body glucose kinetic data are shown in Table 1. Under basal conditions, plasma glucose was $28 \%$ lower in the pregnant compared to virgin rats. Basal insulin levels were not different. Total Ra or HGP was $22 \%$ higher and MCR was $73 \%$ higher in the pregnant compared to virgin rats. Under the clamp conditions, as planned, the plasma glucose level achieved for the pregnant rats was not different from the virgin rats. This level was significantly higher than the basal level for the pregnant rats $(p<0.01)$. The clamp plasma insulin levels were not matched between groups being $54 \%$ higher in the pregnant rats. In order to achieve matched plasma glucose levels, the GIR for the pregnant compared to virgin rats was $69 \%$ higher. Total $\mathrm{Ra}$ and MCR were again significantly higher in the pregnant compared to virgin rats in the clamp studies. HGP was suppressed during the clamps by $41 \%$ from basal in 
Table 2. Plasma glucose specific activity levels at sampling times during the glucose infusion studies in virgin and pregnant rats

\begin{tabular}{lll}
\hline $\begin{array}{l}\text { Plasma glucose specific } \\
\text { activity }(\mathrm{dpm} / \mu \mathrm{mol})\end{array}$ & Virgin & Pregnant \\
\hline $\begin{array}{lll}\text { Basal } \\
100 \mathrm{~min}\end{array}$ & $12290 \pm 2660$ & $9390 \pm 1640$ \\
$110 \mathrm{~min}$ & $13020 \pm 2970$ & $9205 \pm 1632$ \\
$120 \mathrm{~min}$ & $12390 \pm 2620$ & $9016 \pm 1410$ \\
Low glucose infusion period & & \\
$160 \mathrm{~min}$ & $12610 \pm 1624$ & $12200 \pm 1110$ \\
$170 \mathrm{~min}$ & $12990 \pm 1533$ & $12660 \pm 1280$ \\
$180 \mathrm{~min}$ & $13560 \pm 1900$ & $13670 \pm 1280^{\mathrm{a}}$ \\
High glucose infusion period & & \\
$220 \mathrm{~min}$ & $11850 \pm 1530$ & $12070 \pm 730$ \\
$230 \mathrm{~min}$ & $11820 \pm 1392$ & $12750 \pm 880$ \\
$240 \mathrm{~min}$ & $11390 \pm 1243$ & $12480 \pm 700$ \\
\hline
\end{tabular}

Values are means \pm SEM of 6 rats in each group. ${ }^{a} p<0.05$ vs pregnant 160 min using paired $t$-test

the virgin rats and by $90 \%$ from basal in the pregnant rats.

Glucose infusion studies. Plasma glucose specific activity results for these studies are shown in Table 2. Plasma glucose specific activities were at steady state for the $20 \mathrm{~min}$ of sampling during the basal and the high-dose glucose infusion periods in both groups. Glucose specific activity, however, tended to increase throughout the $20 \mathrm{~min}$ sampling period of the lowdose glucose infusions in both the pregnant and virgin rats $(12 \%$ and $8 \%$, respectively); being significant in the pregnant rats only. The addition of $\left[6-^{3}-\mathrm{H}\right]$ glucose tracer to the glucose infusates successfully avoided large changes in glucose specific activity such that the small rises in glucose specific activity in the lowdose glucose infusion periods of both groups were most probably due to small, but real, reductions in HGP over the time of sampling. The reported HGP results for the low-dose glucose infusion periods, calculated using the steady-state formula, were not different to the results calculated using the non-steadystate formula of Steele [25].

The plasma glucose, insulin and whole-body glucose kinetic results for these studies are shown in
Table 3. The pattern of basal glucose kinetics was not different to that described above. The measured low- and high-glucose infusion rates, expressed per unit of rat weight, tended to be slightly higher in the pregnant than the virgin rats; but the differences were not statistically significant. The plasma insulin levels measured during the low- and high-glucose infusion periods were $47 \%$ and $116 \%$ higher in the pregnant rats, respectively, compared to the corresponding levels in the virgin rats. The plasma glucose level remained lower and the plasma glucose MCR levels remained higher in the pregnant compared to virgin rats during the glucose infusion periods; although these differences were only significant for the low-glucose infusion period. HGP, expressed per unit of rat weight, was suppressed to similar levels in both groups during the respective glucose infusion periods.

The dose-responses of plasma insulin to plasma glucose and the percentage suppression of HGP to plasma glucose for the pregnant and virgin rats are shown in Figure 1A and B, respectively. Both were markedly shifted to the left in the pregnant rats. The dose-responses of the percentage suppression of HGP to plasma insulin and the increment in plasma glucose MCR to plasma insulin for the pregnant and virgin rats are shown in Figure $2 \mathrm{~A}$ and $\mathrm{B}$, respectively. The dose-responses of the percentage suppression of HGP to plasma insulin were not different between the groups. The dose-response of the increment in plasma glucose MCR to plasma insulin, however, was shifted to the right in the pregnant compared to virgin rats.

\section{Discussion}

The present studies show that HGP suppression by insulin is not impaired during late pregnancy in the rat. Furthermore, this suppression occurs, in association with the stimulation of insulin secretion, at a lower level of glycaemia than in virgin rats. These results indicate that the set point for plasma glucose homeostasis is lowered during late pregnancy in the rat due

Table 3. Plasma glucose and insulin levels, GIR, Total Ra, HGP and MCR during the basal, low glucose infusion (Low G. Inf.) and high glucose infusion (High G. Inf.) periods in virgin and pregnant rats

\begin{tabular}{|c|c|c|c|c|c|c|}
\hline & \multicolumn{3}{|l|}{ Virgin } & \multicolumn{3}{|l|}{ Pregnant } \\
\hline & Basal & Low G. Inf. & High G. Inf. & Basal & Low G. Inf. & High G. Inf. \\
\hline Glucose (mmol/l) & $5.7 \pm 0.3$ & $6.9 \pm 0.3$ & $8.4 \pm 0.6$ & $4.3 \pm 0.1^{b}$ & $5.5 \pm 0.2^{\mathrm{e}}$ & $7.7 \pm 0.4$ \\
\hline Insulin $(\mathrm{pmol} / \mathrm{l})$ & $68 \pm 11$ & $104 \pm 11$ & $152 \pm 14$ & $94 \pm 9$ & $147 \pm 10^{c}$ & $326 \pm 27^{\mathrm{f}}$ \\
\hline $\mathrm{GIR}\left(\mu \mathrm{mol} \cdot \mathrm{kg}^{-1} \cdot \mathrm{min}^{-1}\right)$ & - & $54 \pm 4$ & $134 \pm 9$ & - & $60 \pm 2$ & $151 \pm 5$ \\
\hline Total Ra $\left(\mu \mathrm{mol} \cdot \mathrm{kg}^{-1} \cdot \mathrm{min}^{-1}\right)$ & $48 \pm 3$ & $89 \pm 3$ & $158 \pm 10$ & $56 \pm 5$ & $93 \pm 4$ & $169 \pm 10$ \\
\hline $\mathrm{HGP}\left(\mu \mathrm{mol} \cdot \mathrm{kg}^{-1} \cdot \min ^{-1}\right)$ & $48 \pm 3$ & $35 \pm 4$ & $24 \pm 3$ & $56 \pm 5$ & $33 \pm 4$ & $18 \pm 8$ \\
\hline $\mathrm{MCR}\left(\mathrm{ml} \cdot \mathrm{kg}^{-1} \cdot \mathrm{min}^{-1}\right)$ & $8.5 \pm 0.2$ & $13.0 \pm 0.6$ & $19.4 \pm 2.2$ & $13.1 \pm 1.2^{\mathrm{a}}$ & $17.0 \pm 0.9^{\mathrm{d}}$ & $22.3 \pm 2.0$ \\
\hline
\end{tabular}

Values are means \pm SEM of 6 rats in each group. ${ }^{\mathrm{a}} p<0.05,{ }^{\mathrm{b}} p<0.005$ vs basal virgin. ${ }^{\mathrm{c}} p<0.05,{ }^{\mathrm{d}} p<0.01,{ }^{\mathrm{e}} p<0.005$ vs low glucose infusion virgin. ${ }^{\mathrm{f}} p<0.001$ vs high glucose infusion virgin 

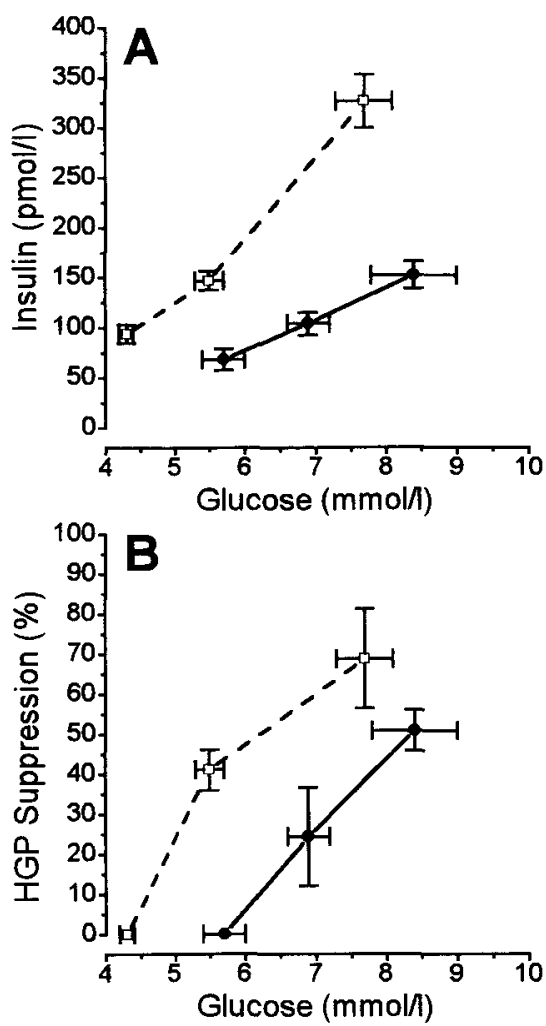

Fig. 1 A, B. Dose-responses of (A) plasma insulin to plasma glucose and (B) the percentage suppression of hepatic glucose production (HGP) to plasma glucose during the glucose infusion studies in virgin $\longrightarrow(n=6)$ and pregnant $--\square-(n=6)$ rats

to adaptations in the pancreatic islet-hepatic axis. It is also apparent from these studies, that despite the well-documented peripheral insulin resistance of late pregnancy, overall glucose assimilation is enhanced at this stage in the pregnant rat.

The hyperinsulinaemic euglycaemic clamp studies convincingly show that HGP is almost totally suppressible in the pregnant rat at only moderate levels of hyperinsulinaemia $(\sim 240 \mathrm{pmol} / \mathrm{l})$. This is at wide variance with the results of Rossi et al. [17] who also performed hyperinsulinaemic euglycaemic clamp studies in unstressed, chronically catheterised conscious rats. They found that in late pregnancy HGP was suppressible by only $20-30 \%$ at extremely high levels of maternal plasma insulin $(\sim 1700-2400 \mathrm{pmol} / \mathrm{l})$. The main difference between their study and the present one was the level of glycaemia at which the pregnant rats were clamped (4.0-4.1 $\mathrm{mmol} / \mathrm{l}$ in Rossi et al. [17] vs $6.1 \mathrm{mmol} / 1$ in the present study). These varying results suggest that the ability of insulin to suppress HGP, at least in pregnancy, does depend on the level of the prevailing plasma glucose. It also needs to be taken into account, however, that the period of food removal prior to metabolic testing was quite long ( $24 \mathrm{~h})$ in the study of Rossi et al. [17], as it was also in some of the rabbit studies $(18 \mathrm{~h})[18,19]$;
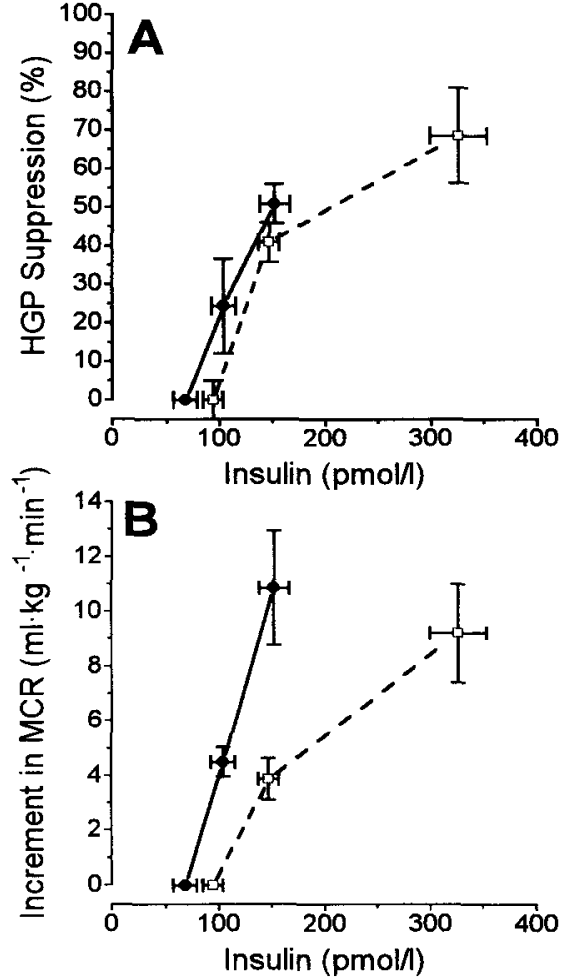

Fig. 2 A, B. Dose-responses of (A) the percentage suppression of hepatic glucose production (HGP) to plasma insulin and (B) the increment in the plasma glucose metabolic clearance rate to plasma insulin during the glucose infusion studies in virgin $\longrightarrow(n=6)$ and pregnant $--\square--(n=6)$ rats

whereas food was removed only $4 \mathrm{~h}$ prior to the commencement of metabolic testing in the current study. It has been shown in non-pregnant anaesthetised rats, that prolonged fasting ( 3 days) impairs the ability of insulin to both suppress HGP and promote peripheral glucose utilisation [26]. It may be that the 24-h fast in the pregnant rats in the study of Rossi et al. [17] was equivalent to a 3-day fast in non-pregnant rats due to the well-described phenomenon of 'accelerated starvation' of pregnancy $[1,2,4]$.

Conclusions concerning differences in peripheral and hepatic insulin sensitivity between the virgin and pregnant rats cannot be made from the current clamp studies as the insulin levels achieved were different between the groups. The higher insulin levels in the pregnant rat clamps were almost certainly due to endogenous release of insulin from the maternal beta cells in response to the small rise in glycaemia. It is becoming clear, therefore, that the hyperinsulinaemic euglycaemic clamp has serious limitations when it comes to comparing the insulin sensitivity of pregnant and non-pregnant groups. Correction of the disparity between the basal glucose levels in the clamps results in either elevated endogenous insulin levels in the pregnant rats (if the glucose level of the pregnant group is raised) or an imbalance in the 
counter-regulatory hormones (if the glucose level of the non-pregnant group is lowered).

The glucose infusion studies were performed in order to assess the control of endogenous glucose production during pregnancy in the more physiological circumstances of concurrently raised plasma insulin and glucose levels. These studies also had a further advantage over the clamp studies in that the only source of insulin was entirely endogenous. The doseresponses of plasma insulin to plasma glucose (Fig. 1A) and the percentage suppression of hepatic glucose production to plasma glucose (Fig. 1B) were similar in that both were markedly shifted to the left in the pregnant rats. Both these results indicate that the maternal glucose set point is lowered in late pregnancy in the rat. It is also clearly apparent from Figure $1 \mathrm{~A}$ that the beta cell is hyperresponsive to glucose in pregnancy, as is indicated by the increased slope of the response. The shift of the insulin to glucose dose-response curve is consistent with previous reports $[27,28]$, as is the hyperresponsiveness of insulin secretion to glucose [1-3, 13-15].

The molecular basis of the adaptation in the maternal beta cells to late pregnancy is not known, but there is considerable evidence which implicates the gestational hormones oestrogen $[3,14]$, progesterone $[3,14]$ and placental lactogen $[3,27,28]$ as being important. It is also interesting to speculate that elevated non-esterified fatty acids (NEFA), as found in pregnancy, may have a role in the beta cell adaptation as it has been shown that exposure to NEFA increase low $K_{m}$ glucose usage in cultured normal islets [29]. Undoubtedly the stimulation of insulin release at a lowered glucose level will be a major contributor to the lowered glucose set point for HGP suppression. It is not possible to determine from these studies, however, whether intrinsic adaptation of the hepatocyte to late pregnancy also contributes to the plasma glucose set point lowering. The glucose set point for the suppression of glucagon secretion has not been explored in the current studies but could potentially be important to the control of HGP. Enhanced suppression of glucagon by glucose late in pregnancy has been shown in human pregnancy [30].

The dose-responses of the percentage suppression of HGP to plasma insulin (Fig. 3A), were not different between the pregnant and virgin groups, at least within the insulin ranges which overlapped $(\sim 90$ $150 \mathrm{pmol} / \mathrm{l})$. Direct comparison of hepatic insulin sensitivity is again difficult, however, as disparity exists in the levels of glycaemia between groups for any given insulin level. Nevertheless, the finding that HGP was suppressed to a similar degree in both groups ( $41 \pm 5$ vs $51 \pm 5 \%$ from basal, $\mathrm{P}$ vs V; N.S.) at matched insulin levels ( $147 \pm 10$ vs $152 \pm 14 \mathrm{pmol} / \mathrm{l}$, $\mathrm{P}$ vs V; N.S.) but at plasma glucose levels which were much lower in the pregnant rats $(5.5 \pm 0.2$ vs $8.4 \pm 0.6 \mathrm{mmol} / 1, \mathrm{P}$ vs $\mathrm{V} ; p<0.0001)$, is very suggestive that the pregnant compared to virgin liver is at least as sensitive to insulin. This finding is therefore more in keeping with the results of the previously reported sheep [20] and human [7] clamp studies, both of which failed to show maternal hepatic insulin resistance late in pregnancy.

Glucose assimilation in the pregnant compared to virgin rats was shown to be enhanced during the clamp studies. The GIR required to maintain plasma glucose at about $6 \mathrm{mmol} / 1$ was $68 \%$ higher if expressed per unit of rat weight, or $99 \%$ higher if expressed per whole rat $(p<0.005)$, in the pregnant compared to virgin rats. Glucose assimilation was also shown to be enhanced in the pregnant rats during the lower dose glucose infusion of $60 \mathrm{mmol} \cdot \mathrm{kg}^{-1}$. $\mathrm{min}^{-1}$, as plasma glucose remained significantly lower in this group. The higher GIR of $150 \mathrm{mmol} \cdot \mathrm{kg}^{-1}$. $\mathrm{min}^{-1}$ resulted in similar glucose levels in both groups. It is important to realise, however, that the former rate of glucose supply is more physiological than the latter higher rate. The reduced slope of the dose-response of the increment in MCR to plasma insulin in the pregnant rats (Fig. 2B) is consistent with there being peripheral insulin resistance. While the peripheral insulin resistance should have the effect of impeding glucose assimilation in the pregnant rats, this was not manifest in either study, most probably due to the counteractive effects of the beta-cell hyperresponsiveness and effective suppression of HGP.

The basal results in both the clamp and glucose infusion studies are consistent with those of previous investigators [5-7] in addition to our own previous work [4]. In late pregnancy under basal conditions, plasma glucose is lowered despite there being an increased influx of glucose from the maternal liver. As previously reported from our laboratory, this can be explained by the effect of glucose loss to the feto-placental unit or the 'feto-placental glucose steal phenomenon' [4]. The previously reported finding that fasting hypoglycaemia also occurs early in pregnancy $[5,31]$, at which time a significant feto-placental glucose steal is not operative, suggests that other influences (most probably hormonal) are also involved in the lowering of the glucose homeostasis set point. Interestingly, beta-cell hyperresponsiveness develops early in pregnancy $[31,32]$ and this is associated with enhanced glucose assimilation at that stage [2]. Ogata et al. [5], on the basis of basal findings, also concluded that there was lowering of the plasma glucose set point in pregnancy.

With respect to hepatic metabolism, the current studies have only assessed the responsiveness of HGP suppression to glucose and insulin. The effectiveness of glucose and insulin to promote glucose uptake by the liver and to stimulate glycogen storage in the liver have not been investigated but are obviously important to the overall control of glucose homeostasis in pregnancy. It is possible that the insulin 
sensitive' liver of pregnancy, in response to high postprandial portal insulin levels, may have a significantly enhanced capacity to store glucose in the form of glycogen during the fed state.

We suggest that the adaptations of the pancreatic islet-hepatic axis during pregnancy, which result in the lowering of the plasma glucose set point, are responsible for the process of 'facilitated anabolism' as proposed by Freinkel [1]. In early pregnancy, 'facilitated anabolism' involves both the maternal liver and peripheral tissues with the resultant effect of an accumulation of maternal energy stores predominantly in the form of adipose tissue triglyceride [1, 2]. In late pregnancy, the effects of 'facilitated anabolism' are restricted to the maternal liver due to the development of insulin resistance predominantly within the maternal peripheral tissues. In the fed state, the peripheral insulin resistance spares glucose for use by the feto-placental unit. The maternal liver, however, via 'facilitated anabolism' buffers this spared glucose such that the developing feto-placental unit does not need to deal with marked surges in glucose supply.

In conclusion, major adaptations of the pancreatic islet-hepatic axis occur in normal pregnancy in the rat which result in lowering of the maternal plasma glucose set point. Consideration needs to be given to the mechanisms underlying these adaptations and to the role that they play in the control of glucose homeostasis in both normal and diabetic human pregnancy.

Acknowledgements. We gratefully acknowledge the excellent technical assistance of Ms. L. Wilson, Ms. C. Robinson and Ms. S. Fabris. We wish to thank Professor R. Larkins for his support and helpful comments. This work was supported by an Apex/ Diabetes Australia Research Grant and a Program Grant from the National Health and Medical Research Council of Australia. Dr. C. J. Nolan has been supported by a National Health and Medical Research Council Postgraduate Medical Scholarship.

\section{References}

1. Freinkel N (1980) Banting lecture 1980: Of pregnancy and progeny. Diabetes 29: 1023-1035

2. Knopp RH, Montes A, Childs M, Li JR, Mabuchi H (1981) Metabolic adjustments in normal and diabetic pregnancy. Clin Obstet Gynecol 24: 21-49

3. Kalkhoff RK, Kissebah AH, Kim H-J (1978) Carbohydrate and lipid metabolism during normal pregnancy: relationship to gestational hormone action. Semin Perinatol 2: 291-307

4. Nolan CJ, Proietto J (1994) The feto-placental glucose steal phenomenon is a major cause of maternal metabolic adaptation during late pregnancy in the rat. Diabetologia 37: 976-984

5. Ogata ES, Metzger BE, Freinkel N (1981) Carbohydrate metabolism in pregnancy XVI: longitudinal estimates of the effects of pregnancy on D- $\left(6^{3} \mathrm{H}\right)$ glucose and D- $\left(6-{ }^{14} \mathrm{C}\right)$ glucose turnovers during fasting in the rat. Metabolism 30: $487-492$

6. Kalhan SC, Adam PAJ (1980) Quantitative estimation of systemic glucose production in normal and diabetic pregnancy. Diabetes Care 3: 410-415

7. Catalano PM, Tyzbir ED, Wolfe RR, Roman NM, Amini SB, Sims EAH (1992) Longitudinal changes in basal hepatic glucose production and suppression during insulin infusion in normal pregnant women. Am J Obstet Gynecol 167: 913-919

8. Leturque A, Ferre P, Burnol A-F, Kande J, Maulard P, Girard J (1986) Glucose utilization rates and insulin sensitivity in vivo in tissues of control virgin and pregnant rats. Diabetes 35: 172-177

9. Holness MJ, Changani KK, Sugden MC (1991) Progressive suppression of muscle glucose utilization during pregnancy. Biochem J 280: 549-552

10. Hauguel S, Gilbert M, Girard J (1987) Pregnancy-induced insulin resistance in liver and skeletal muscles of the conscious rabbit. Am J Physiol 252: E165-E169

11. Rushakoff RJ, Kalkhoff RK (1981) Effects of pregnancy and sex steroid administration on skeletal muscle metabolism in the rat. Diabetes 30: 545-550

12. Toyoda N, Murata K, Sugiyama Y (1985) Insulin binding, glucose oxidation, and methylglucose transport in isolated adipocytes from pregnant rats near term. Endocrinology 116: 998-1002

13. Hornnes PJ, Kühl C (1980) Plasma insulin and glucagon responses to isoglycemic stimulation in normal pregnancy and post partum. Obstet Gynecol 55: 425-427

14. Costrini NV, Kalkhoff RK (1971) Relative effects of pregnancy, estradiol and progesterone on plasma insulin and pancreatic islet insulin secretion. J Clin Invest 50: 992-999

15. Buchanan TA, Metzger BE, Freinkel N, Bergman RN (1990) Insulin sensitivity and B-cell responsiveness to glucose during late pregnancy in lean and moderately obese women with normal glucose tolerance or mild gestational diabetes. Am J Obstet Gynecol 162: 1008-1014

16. Leturque A, Burnol AF, Ferré P, Girard J (1984) Pregnancy-induced insulin resistance in the rat: assessment by glucose clamp technique. Am J Physiol 246: E25-E31

17. Rossi G, Sherwin RS, Penzias AS et al. (1993) Temporal changes in insulin resistance and secretion in 24-h-fasted conscious pregnant rats. Am J Physiol 265: E845-E851

18. Gilbert M, Pere MC, Baudelin A, Battaglia FC (1991) Role of free fatty acids in hepatic insulin resistance during late pregnancy in conscious rabbits. Am J Physiol 260: E938E945

19. Gilbert M, Basile S, Baudelin A, Pere MC (1993) Lowering plasma free fatty acid levels improves insulin action in conscious pregnant rabbits. Am J Physiol 264: E576-E582

20. Hay WW, Lin C-C, Meznarich HK (1988) Effect of high levels of insulin on glucose utilization and glucose production in pregnant and nonpregnant sheep. Proc Soc Exp Biol Med 189: 275-284

21. Glinsmann WH, Hern EP, Lynch A (1969) Intrinsic regulation of glucose output by rat liver. Am J Physiol 216: 698703

22. Rossetti L, Giaccari A, Barzilai N, Howard K, Sebel G, Hu M (1993) Mechanism by which hyperglycemia inhibits hepatic glucose production in conscious rats. Implications for the pathophysiology of fasting hyperglycemia in diabetes. J Clin Invest 92: 1126-1134

23. Sacca L, Hendler PE, Sherwin RS (1979) Hyperglycemia inhibits glucose production in man independent of changes in glucoregulatory hormones. J Clin Endocrinol Metabol 47: $1160-1163$ 
24. Finegood DT, Bergman RN, Vranic M (1988) Modelling error and apparent isotope discrimination confound estimation of endogenous glucose production during euglycemic glucose clamps. Diabetes 37: 1025-1034

25. Steele R (1959) Influences of glucose loading and injected insulin on hepatic glucose output. Ann NY Acad Sci 82: $420-430$

26. Penicaud L, Kande J, Le Magnen J, Girard JR (1985) Insulin action during fasting and refeeding in rat determined by euglycemic clamp. Am J Physiol 249: E514-E518

27. Sorenson RL, Parsons JA (1985) Insulin secretion in mammosomatotropic tumor-bearing and pregnant rats. A role for lactogens. Diabetes 34: 337-341

28. Parsons JA, Brelje TC, Sorenson RL (1992) Adaptation of islets of Langerhans to pregnancy: increased islet cell proliferation and insulin secretion correlates with the onset of placental lactogen secretion. Endocrinology 130: 14591466

29. Unger R (1995) Lipotoxicity in the pathogenesis of obesitydependent NIDDM. Genetic and clinical implications. Diabetes 44: 863-870

30. Kühl C, Holst JJ (1976) Plasma glucagon and the insulin: glucagon ratio in gestational diabetes. Diabetes 25: 16-23

31. Buch I, Hornnes PJ, Kühl C (1986) Glucose tolerance in early pregnancy. Acta Endocrinologica 112: 263-266

32. Spellacy WN, Goetz FC, Greenberg BZ, Ells J (1965) Plasma insulin in normal "early" pregnancy. Obstet Gynecol 25: $862-865$ 